\title{
Do Wolbachia influence fecundity in Nasonia vitripennis?
}

\author{
SETH R. BORDENSTEIN* \& JOHN H. WERREN \\ Department of Biology, The University of Rochester, Rochester, NY 14627, U.S.A.
}

\begin{abstract}
This paper reports the influence of a vertically transmitted symbiont, Wolbachia, on host fitness in the parasitic wasp, Nasonia vitripennis. We measured fecundities of uninfected strains and strains infected with either two Wolbachia variants $(w \mathrm{Av}, w \mathrm{Bv})$ or one ( $w \mathrm{Av}$ or $w \mathrm{Bv})$. Preliminary tests suggested that double-infected females produce more offspring on average than uninfected females. However, further studies failed to yield consistent fitness effects. To control for host genetic effects, the genotype of the double-infected and uninfected strain was 'replaced' with three different host genetic backgrounds by introgression. Contrary to previous results, we found no convincing evidence for positive fitness effects of Wolbachia in Nasonia vitripennis, once host genetic background was controlled for. It can be concluded that under the experimental design used here, the fecundity effects associated with Wolbachia in $N$. vitripennis are small or absent.
\end{abstract}

Keywords: fecundity, Nasonia vitripennis, reproductive parasite, symbiosis, vertical transmission, Wolbachia.

\section{Introduction}

There is a long-standing prediction that vertically transmitted symbionts will be selected to increase host survival and reproduction (Fine, 1975; Ewald, 1987; Yamamura, 1993; Lipsitch et al., 1995). The basic reason is that maximization of host reproductive success benefits both symbiont and host, because both parties share the same route into the next generation - the host's gametes. However, classical mutualistic symbiosis is not the only evolutionary trajectory for vertically transmitted symbionts. Assuming cytoplasmic inheritance through eggs, as most vertically transmitted symbionts have, other trajectories exist that can facilitate the spread of inherited symbionts. Characterized as 'reproductive parasitism', these include: (i) manipulation of host sex ratio towards the transmitting sex; and (ii) cytoplasmic incompatibility (reviewed in Werren \& O'Neill, 1997). Generally, selection on the symbiont operates only on females, as males are an evolutionary 'dead end' for maternally inherited cytoplasmic elements. Therefore, inherited symbionts can be selected to decrease fitness of infected males, if that increases fitness of infected females. Examples include male-killing microorganisms (reviewed in Hurst \& Majerus, 1993) and cytoplasmic incompatibility (reviewed in Hoffman \& Turelli, 1997 and Werren, 1997).

*Correspondence. E-mail: sbst@troi.cc.rochester.edu
This study investigates the effects of Wolbachia on host fitness in the parasitic wasp, Nasonia vitripennis. Wolbachia are cytoplasmically inherited intracellular bacteria that infect the reproductive tissues of arthropods. Wolbachia are extremely widespread and infect $\sim 20 \%$ of all insect species (Werren et al., 1995a). They have also been found in mites, isopods and nematodes (Rousset et al., 1992; Johanowicz \& Hoy, 1995; Sironi et al., 1995). Wolbachia are a model system for the study of 'reproductive parasites', because they cause a wide range of reproductive modifications, including parthenogenesis in wasps (Stouthamer et al., 1993), feminization in terrestrial isopods (Rousset et al., 1992), possible modulation of sperm competition in Tribolium beetles (Wade \& Chang, 1995), and cytoplasmic incompatibility (CI) in a variety of insect species (Yen \& Barr, 1971; Hoffman et al., 1986; Breeuwer \& Werren, 1990; O’Neill \& Karr, 1990; Werren, 1997).

$\mathrm{CI}$ is the most common phenomenon caused by Wolbachia. It is phenotypically expressed as embryo mortality in diploid species or as a sex ratio shift biased towards the haploid sex (male) in haplodiploid species. In both cases, it appears to be caused by improper functioning of the paternal pronucleus following fertilization (Ryan \& Saul, 1968; Reed \& Werren, 1995; Callaini et al., 1997). CI occurs in crosses between infected males and uninfected females, or between males and females that harbour different Wolbachia strains. Because of the benefits of CI (reduced fitness of 
uninfected females), CI-Wolbachia can increase in frequency, even if they cause some reduction in fecundity of infected females (Turelli, 1994). However, selection on Wolbachia still favours those variants that minimize fecundity costs for infected females, and can even lead to mutualistic associations of CI-Wolbachia and their hosts (Turelli, 1994).

Fitness effects attributed to Wolbachia have been described in several infected species (Table 1). Results reported so far range from permanent changes in fitness (effect persists for many generations after curing) to temporary changes (effect persists for a few generations after curing), and from positive to negative fitness effects. For example, studies attribute permanent negative fitness effects to Wolbachia in Drosophila simulans (Hoffmann et al., 1990), but positive fitness effects have been reported in the wasp, Nasonia vitripennis (Stolk \& Stouthamer, 1996) and the stalk eye fly, Sphyracephala beccarii (Hariri et al., 1998). In each of these species, the Wolbachia induce CI. In an additional case in which Wolbachia induce parthenogenesis, infected females of two Trichogramma wasp species have reduced offspring numbers over their lifetime in comparison to their uninfected counterparts (Stouthamer \& Luck, 1993).

Here we investigate fecundity effects of CI-Wolbachia in N. vitripennis (Breeuwer \& Werren, 1990; PerrotMinnot et al., 1996). Nasonia vitripennis typically harbour double Wolbachia infections from each of the two major phylogenetic groups - A and B. These two groups are estimated to have diverged $60 \mathrm{Ma}$ (Werren et al., 1995b) and constitute different CI types that are mutually incompatible (Perrot-Minnot et al., 1996).
Segregation experiments in the laboratory have shown that single-infected stocks can be generated following prolonged diapause (Perrot-Minnot et al., 1996). In this work, we address the following questions.

1 Do single and/or double Wolbachia infections influence fecundity in $N$. vitripennis? If so, do different Wolbachia strains exert different fecundity effects?

2 Can host genotype explain potential fitness effects attributed to Wolbachia? When experiments compare fitness traits of infected and uninfected hosts, uninfecteds are typically generated in the laboratory by antibiotic, heat or diapause treatment. These treatments create a problem in experimental designs: the stocks are subject to bottlenecks that can fix or increase the frequency of nuclear alleles that affect fitness. As a result, the cause of a fitness difference between infecteds and uninfecteds can spuriously be attributed to Wolbachia, rather than changes in host nuclear genes.

3 Does host genotype influence the level of fecundity effects associated with Wolbachia?

In this study, we investigate fecundity effects associated with both Wolbachia and the host nuclear genome of $N$. vitripennis. Along the way, we highlight methodological issues related to measuring fecundity effects of cytoplasmically inherited bacteria.

\section{Materials and methods}

Nasonia wasps are gregarious parasitoids of pupal fly hosts and are raised on Sarcophaga bullata blowflies in

Table 1 Studies of host fitness effects attributed to Wolbachia

\begin{tabular}{|c|c|c|c|c|}
\hline Species & Effect & $\begin{array}{l}\text { Female }(\mathrm{F}) \\
\text { or male }(\mathrm{M})\end{array}$ & $\begin{array}{l}\text { Permanent }(\mathrm{P}) \\
\text { or temporary }(\mathrm{T})\end{array}$ & References \\
\hline Drosophila simulans & Negative & $\mathrm{F}$ & $\mathrm{P}$ & $\begin{array}{l}\text { Hoffmann \& Turelli (1988), } \\
\text { Hoffmann et al. (1990) }\end{array}$ \\
\hline $\begin{array}{l}\text { Trichogramma deion } \\
\text { and T. pretiosum }\end{array}$ & Negative & $\mathrm{F}$ & $P$ & $\begin{array}{l}\text { Stouthamer \& Luck (1993), } \\
\text { Stouthamer (pers. comm.) }\end{array}$ \\
\hline Drosophila melanogaster & None & $\mathrm{F}$ & ND & Hoffman et al. (1994) \\
\hline Drosophila mauritiana & None & $\mathrm{F}$ & ND & Giordano et al. (1995) \\
\hline Tribolium confusum & Negative/positive & $\mathrm{F} / \mathrm{M}$ & $\mathrm{P}$ & Wade \& Chang (1995) \\
\hline Trichogramma bourarachae & Positive & $\mathrm{F}$ & $\mathrm{P}$ & Girin \& Bouletreau (1995) \\
\hline Drosophila simulans & None & $\mathrm{F}$ & ND & Hoffmann et al. (1996) \\
\hline $\begin{array}{l}\text { Drosophila ananassae } \\
\text { and D. sechellia }\end{array}$ & None & $\mathrm{F}$ & ND & Bourtzis et al. (1996) \\
\hline Nasonia vitripennis & Positive & $\mathrm{F}$ & ND & Stolk \& Stouthamer (1996) \\
\hline Drosophila simulans & Positive & $\mathrm{F}$ & $\mathrm{T}$ & Poinsot \& Mercot (1997) \\
\hline Sphyracephala beccarii & Positive & M & ND & Hariri et al. (1998) \\
\hline Trichogramma bourarachae & Positive & $\mathrm{F}$ & ND & Vavre et al. (1999) \\
\hline
\end{tabular}

The fitness trait may be measured in females, males or both, and the effect may be temporary (i.e. limited to a small number of generations following curing), permanent or the duration not determined (ND).

(C) The Genetical Society of Great Britain, Heredity, 84, 54-62. 
the lab. The biology of Nasonia is reviewed in Whiting (1967). Generation time is two weeks at $25^{\circ} \mathrm{C}$. Nasonia have haplodiploid genetic sex determination. Females are diploid and can only develop from fertilized eggs. Males are haploid and develop from unfertilized eggs. Thus, unmated females are fecund and lay all-male progeny.

\section{Strains}

The strains were reared in constant light at $25^{\circ} \mathrm{C}$. Fecundity tests were conducted with double-infected $(A B)$, single-infected (A or B), and uninfected strains. All nonintrogression strains were derived from a doubleinfected female by diapause treatment. Previous studies indicated that prolonged diapause can cause a 'natural' loss of the bacteria in $N$. vitripennis (Perrot-Minnot et al., 1996). Bacterial densities decline during prolonged diapause, and eventually one or both bacterial types can be stochastically lost. Sublines were thus produced from a double-infected diapaused stock (R511, 18 months in diapause) that was derived from a single inseminated female in 1996. The lines were not exposed to antibiotics, eliminating the effects of antibiotics as a variable influencing fitness. A complete history of the lines is given in Perrot-Minnot et al. (1996).

Infection status of these lines is indicated by a lower case $w$ for Wolbachia, an upper case A or B to denote the subgroup, and a lower case $\mathrm{v}$ for $N$. vitripennis. There are four sets of infections: the double infection, $w \mathrm{Av}, w \mathrm{Bv}$; each of the single infections, $w \mathrm{Av}$ and $w \mathrm{Bv}$; and the uninfecteds, $0 \mathrm{v}$.

The following lines were used for fecundity tests. R511 is double-infected; $12.1,15.12$, and 15.12.3 are $w \mathrm{Av}$ infected; $4.9,13.5$ and 1.2 are $w \mathrm{Bv}$ infected; and 13.2 and 8.3 are uninfected. Infection status was confirmed by PCR using primers previously described in Perrot-Minnot et al. (1996).

Three additional $N$. vitripennis strains were used for nuclear introgression experiments described below. These strains are: (i) Red833R, a red eye mutant cured of its infection by heat shock in 1989; (ii) AsymC, a laboratory strain cured of its infection by heat shock in 1989; and (iii) 13.2, a strain naturally cured of its infection by a diapause treatment experiment described in Perrot-Minnot et al. (1996).

\section{Introgression}

Differences in fitness between lines could be caused by effects of Wolbachia, or by differences in host genotype. To control for host nuclear effects, the genotypes of the $w \mathrm{Av}, w \mathrm{Bv}$ infected strain (1.1), and the uninfected $0 \mathrm{v}$ strain (13.2), from which initial comparisons showed a significant difference in fecundity, were replaced by introgression with three genetic backgrounds Red833R, AsymC and 13.2. Lines were started with crosses between uninfected Red833R, AsymC and 13.2 males and females from the double-infected 1.1 and the uninfected 13.2. Introgressing the genotype of 13.2 was particularly informative because: (i) it was the uninfected strain used in the initial fecundity tests; and (ii) its genotype was derived from the same isofemale line as the infected 1.1 (see above). Each generation, the same male from each of the three independent genomes was mated to both the double and uninfected females. Resulting hybrid females were backcrossed to the cured males of the paternal species for six generations. By this method, the derived lines were highly similar genetically, although they differed in infection status. To control for a difference in first and second mating during the six backcross generations, males were alternated for matings to the maternal lines at each generation. Upon completion of the introgression, lines were maintained by sibmating without further backcrossing. Infection status was confirmed by PCR with primers previously described in Perrot-Minnot et al. (1996).

\section{Fecundity assays with virgin females}

Virgin females were collected as pupae. During virgin collections, we controlled for head width because this character is correlated with fecundity in Nasonia (Werren, unpubl. obs.). Pupae were sorted into groups of 16 and each group was placed in a clear $12 \times 75 \mathrm{~mm}$ vial. Upon emergence, single females were provided with four Sarcophaga bullata hosts in a clear vial. We note that use of colour-coded vials to identify strains can skew results, because colours can result in differential heating of tubes (under light) that, in turn, can affect fecundity. Vials were sorted into racks to randomize any effects of microhabitat differences in the incubator (i.e. light, heat). Wasps were allowed to feed and increase egg production on these hosts for $48 \mathrm{~h}$. After this time, virgin females were transferred to a single fresh host for $6 \mathrm{~h}$. From these single hosts, adult offspring numbers were scored. We limited ovipositioning time in all experiments to prevent wasps from becoming resource-limited. This was confirmed in preliminary tests. Because virgin females were used, all-male families resulted, owing to the haplodiploid sex determination of Nasonia.

To follow long-term 'permanent' fitness effects in $N$. vitripennis, second, third, and fourth experiments were conducted one, 14, and 18 generations after the first experiment, described above. All methods were identical to those above with two exceptions. The ovipositioning time for the assay was changed to $5 \mathrm{~h}$, and in the 18th generation experiment, females were set on hosts for $5 \mathrm{~h}$ and then directly transferred to fresh 
hosts for an additional $5 \mathrm{~h}$. From these single hosts, offspring emerged approximately two weeks later and were scored upon death to determine fecundity.

\section{Fecundity assay with mated females}

Male and female pupae were collected and sorted according to the methods above, 43 generations after the first experiment. Upon emergence, within-strain single-pair matings were set up. Three hours later, males were transferred out of the tube and each female was given four Sarcophaga bullata hosts for egg laying and feeding. Vials were again randomized in the racks. Forty-eight hours later, females were then set singly on one host for $5 \mathrm{~h}$ and directly transferred to a fresh host for an additional $5 \mathrm{~h}$. From these two egg-laying periods, the number of males, females, diapause and total offspring were scored.

\section{Statistics}

Pairwise comparisons of adult family sizes were conducted with nonparametric Mann-Whitney $U$-tests, as some distributions were not normal. A sequential Bonferroni test was used to correct for multiple comparisons (Holm, 1979). An overall significance level for a particular comparison was calculated by combining probabilities from independent tests following Fisher (1954) and Sokal \& Rohlf (1981). Anovas were conducted with MINITAB 12.

\section{Results}

\section{Fitness effects without controlling for host genotype}

Fitness effects associated with Wolbachia infections were tested by comparing the fecundity of double- and singleinfected females to uninfecteds, all of which were originally derived from a common strain (PerrotMinnot et al., 1996). Five replicate experiments were conducted over 43 generations. Overall, double-infected $w \mathrm{Av}, w \mathrm{Bv}$ females produced significantly more adult offspring than uninfected $0 \mathrm{v}$ females in four of the five replicate experiments.

In the first experiment, the mean offspring numbers produced over a 6-h ovipositioning period by doubleinfected $(w \mathrm{Av}, w \mathrm{Bv})$, each single-infected ( $w \mathrm{Av}$ and $w \mathrm{Bv})$, and uninfected $(0 \mathrm{v})$ females are shown in Table 2. A difference was found between $w \mathrm{Av}, w \mathrm{Bv}$ and $0 \mathrm{v}$ females $(P=0.0328)$, but the Bonferroni correction makes this a marginally significant result, suggesting that multiple infections may confer a benefit to their $N$. vitripennis host.
Table 2 Female fecundity in unintrogressed lines of Nasonia vitripennis infected and uninfected with Wolbachia

\begin{tabular}{|c|c|c|c|c|}
\hline $\begin{array}{l}\text { Genera- } \\
\text { tion }\end{array}$ & $\begin{array}{l}\text { Oviposi- } \\
\text { tion }\end{array}$ & $\begin{array}{l}\text { Infection } \\
\text { status }\end{array}$ & $\begin{array}{l}\text { Total } \\
\text { (SD) }\end{array}$ & $N$ \\
\hline 0 & & $\begin{array}{c}w \mathrm{Av} \\
w \mathrm{Bv} \\
w \mathrm{Av}, w \mathrm{Bv} \\
0 \mathrm{v}\end{array}$ & $\begin{array}{l}37.59(10.02) \\
39.72(11.21) \\
43.03(13.77) \\
38.64(10.44)\end{array}$ & $\begin{array}{l}70(3) \\
83(3) \\
30(1) \\
57(2)\end{array}$ \\
\hline 1 & & $\begin{array}{c}w \mathrm{Av}, w \mathrm{Bv} \\
0 \mathrm{v}\end{array}$ & $\begin{array}{l}28.64(7.74) \\
23.52(7.43)\end{array}$ & $\begin{array}{l}22(1) \\
44(2)\end{array}$ \\
\hline $14 \dagger$ & & $\begin{array}{c}w \mathrm{Av}, w \mathrm{Bv} \\
0 \mathrm{v}\end{array}$ & $\begin{array}{l}25.00(7.50) \\
26.07(4.55)\end{array}$ & $\begin{array}{l}30(1) \\
31(1)\end{array}$ \\
\hline \multirow[t]{3}{*}{$18 \dagger$} & $1 \mathrm{st}$ & $\begin{array}{c}w \mathrm{Av}, w \mathrm{Bv} \\
0 \mathrm{v}\end{array}$ & $\begin{array}{l}32.64(9.74) \\
27.39(7.94)\end{array}$ & $\begin{array}{l}44(1) \\
38(1)\end{array}$ \\
\hline & 2nd & $\begin{array}{c}w \mathrm{Av}, w \mathrm{Bv} \\
0 \mathrm{v}\end{array}$ & $\begin{array}{l}48.25(13.03) \\
32.93(9.75)\end{array}$ & $\begin{array}{l}48(1) \\
45(1)\end{array}$ \\
\hline & Total & $\begin{array}{c}w \mathrm{Av}, w \mathrm{Bv} \\
0 \mathrm{v}\end{array}$ & $\begin{array}{l}74.96(22.65) \\
52.69(17.39)\end{array}$ & $\begin{array}{l}50(1) \\
48(1)\end{array}$ \\
\hline \multirow[t]{3}{*}{$43 \dagger$} & $1 \mathrm{st}$ & $\begin{array}{c}w \mathrm{Av}, w \mathrm{Bv} \\
0 \mathrm{v}\end{array}$ & $\begin{array}{l}25.31(7.95) \\
23.30(6.66)\end{array}$ & $\begin{array}{l}29(1) \\
20(1)\end{array}$ \\
\hline & 2nd & $\begin{array}{c}w \mathrm{Av}, w \mathrm{Bv} \\
0 \mathrm{v}\end{array}$ & $\begin{array}{l}26.06(7.78) \\
19.95(5.91)\end{array}$ & $\begin{array}{l}31(1) \\
20(1)\end{array}$ \\
\hline & Total & $\begin{array}{c}w \mathrm{Av}, w \mathrm{Bv} \\
0 \mathrm{v}\end{array}$ & $\begin{array}{l}45.32(16.13) \\
39.27(13.60)\end{array}$ & $\begin{array}{l}34(1) \\
22(1)\end{array}$ \\
\hline
\end{tabular}

Total mean offspring numbers (standard deviation) are shown. $N$ is the total number of families scored and the number of pooled strains is shown in parentheses. Oviposition denotes egg laying period. In generations $0-18$, virgin females were used for fecundity tests. In generation 43, mated females were used.

$\dagger$ These tests were conducted concurrently with the introgression experiments and are used as additional controls for those experiments.

In a second experiment conducted one generation later, we confirmed the fecundity difference between the $w \mathrm{Av}, w \mathrm{Bv}$ and $0 \mathrm{v}$ lines $(P=0.0326$, Table 2$)$. In this case, females oviposited for $5 \mathrm{~h}$, which explains why mean offspring numbers are lower than those in the first experiment. Combining the individual outcomes of experiments one and two, following Fisher (1954) and Sokal \& Rohlf (1981), gives an overall significance level of $P<0.01\left(\chi_{4}^{2}=13.68\right)$ for the comparison of fecundities produced by double-infected and uninfected females.

To follow long-term fitness effects, the fecundities of a double-infected and an uninfected strain were tested again in three additional experimental replicates -14 , 18 and 43 generations after the first experiment. These lines also served as 'unintrogressed controls' for fecundity assays with introgression lines (see below). In the 14th generation experiment, no significant difference was found between $w \mathrm{Av}, w \mathrm{Bv}$ and $0 \mathrm{v}$ females (Table 2). 
However, in the 18th generation experiment, comparisons between these same lines showed that doubleinfected females produced more adult offspring than uninfecteds in both ovipositioning periods (1st, $P=0.0149 ; 2$ nd, $P<0.0001)$ and that they produced a greater total number of offspring over both periods $(P<0.0001)$. The 43rd generation experiment was set up similarly, but with mated females. Double-infected females again produced significantly more offspring than uninfecteds, particularly in the second ovipositioning period ( $P=0.0029$, Table 2$)$. The difference in fecundity is most notable in the number of females produced. Infected females produced a greater proportion of daughters than did uninfected females in both the second ovipositioning period $(0.92 \pm 0.06$ vs. $0.86 \pm 0.08, \quad P=0.0033)$ and for total fecundity $(0.91 \pm 0.07$ vs. $0.83 \pm 0.22, P=0.0041)$. The mean number of female offspring produced by double-infected females was higher than uninfected females in the second ovipositioning period (24.76 and 17.53) and for pooled data (42.72 and 32.55).

\section{Fitness effects after controlling for host genotype}

Although the difference between $w \mathrm{Av}, w \mathrm{Bv}$ and $0 \mathrm{v}$ suggests that Wolbachia confer a benefit to their wasp host, an alternative explanation is that host nuclear genes are responsible for the difference in adult brood size. To test for host genetic effects, we introgressed the $w \mathrm{Av}, w \mathrm{Bv}$ cytoplasm from line 1.1 and the $0 \mathrm{v}$ cytoplasm from line 13.2 into three different nuclear backgrounds (Red833R, AsymC, 13.2) for six generations and then measured fecundity differences one generation, four generations, and 30 generations after the introgression was finished. Introgression of the 13.2 genotype is particularly informative because: (i) it is the uninfected 0v strain used in the initial fecundity tests; and (ii) it was originally derived from the same isofemale line as the double-infected 1.1 strain (Perrot-Minnot et al., 1996). Note also that, each generation, the same individual males were used in crosses to the infected and uninfected lines. Because males are haploid and produce nonrecombinant haploid sperm, the genotypes of the resulting infected and uninfected introgression lines will be virtually identical.

One generation postintrogression If Wolbachia unambiguously influence fecundity, our prediction is that Wolbachia will increase fecundity in each of these three genetic backgrounds. Results are shown in Table 3. Fecundities of virgin females that harbour the $w \mathrm{Av}, w \mathrm{Bv}$ and $0 \mathrm{v}$ cytotypes in each of the three host genetic backgrounds were not significantly different (ANOVA, $F_{1,174}=3.52$,

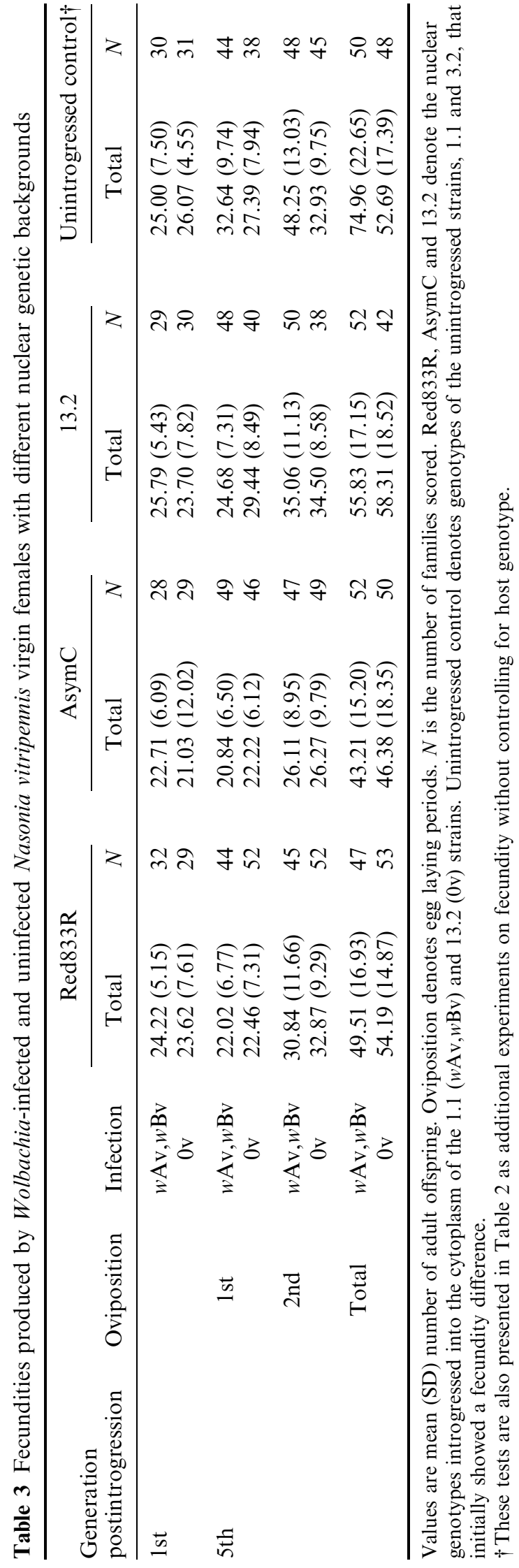

(c) The Genetical Society of Great Britain, Heredity, 84, 54-62. 
Table 4 Analysis of Variance of fecundities of Nasonia vitripennis females infected and uninfected with Wolbachia

\begin{tabular}{|c|c|c|c|c|c|c|c|c|c|c|}
\hline \multirow{2}{*}{$\begin{array}{l}\text { Generation } \\
\text { post-intro- } \\
\text { gression }\end{array}$} & \multirow[b]{2}{*}{ Source } & \multicolumn{3}{|c|}{ 1st five hours } & \multicolumn{3}{|c|}{ 2nd five hours } & \multicolumn{3}{|c|}{ Total } \\
\hline & & d.f. & MS & $F$ & d.f. & MS & $F$ & d.f. & MS & $F$ \\
\hline \multirow[t]{4}{*}{5 th } & Infection & 1 & 301.6 & $5.89^{*}$ & 1 & 20.3 & 0.20 & 1 & 871.5 & 3.30 \\
\hline & Host strain & 2 & 852.8 & $16.67 * * *$ & 2 & 1759.2 & $17.64 * * *$ & 2 & 3709.0 & $14.02 * * *$ \\
\hline & $\begin{array}{l}\text { Infection } \\
\times \text { Host strain }\end{array}$ & 2 & 105.4 & 2.06 & 2 & 41.2 & 0.41 & 2 & 30.7 & 0.12 \\
\hline & Error & 269 & 51.2 & & 275 & 99.7 & & 290 & 264.5 & \\
\hline \multirow{4}{*}{ 30th } & Infection & 1 & 450.0 & $7.58 * *$ & 1 & 0.6 & 0.02 & 1 & 702.5 & $4.07 *$ \\
\hline & Host strain & 2 & 861.3 & $14.51^{* * *}$ & 2 & 353.3 & $8.94 * * *$ & 2 & 3577.4 & $20.74 * * *$ \\
\hline & $\begin{array}{l}\text { Infection } \\
\times \text { Host strain }\end{array}$ & 2 & 30.3 & 0.51 & 2 & 165.1 & $4.18^{*}$ & 2 & 245.3 & 1.42 \\
\hline & Error & 148 & 59.3 & & 153 & 39.5 & & 165 & 172.5 & \\
\hline
\end{tabular}

${ }^{*} P<0.05, * * P<0.01, * * * P<0.001$.

$P>0.05)$. However, the nonintrogression control strains ( $w \mathrm{Av}, w \mathrm{Bv}$ vs. $0 \mathrm{v})$ also were not significantly different, making interpretation of the results difficult.

Five generations postintrogression In this experiment, virgin females were initially set on a single host for $5 \mathrm{~h}$ and then immediately transferred to a fresh host for an additional $5 \mathrm{~h}$. Mean offspring numbers are shown in Table 3. ANOvAs on fecundities are shown in Table 4. Three factors were included in the analyses: infection, host strain and the interaction term. The analyses yielded several results. First, host strain (independent of infection status) was the main factor affecting fecundity. Secondly, infection status had a significant effect in the first ovipositioning period, but not in the second ovipositioning period or total fecundity. The effect is caused by a significant reduction in fecundity of infected females that have the introgressed 13.2 genetic background $(P=0.0170)$. Finally, the interaction term has no effect, meaning that there is no significant interaction between Wolbachia and host genotype on fecundity. These results support a negligible (or slightly negative) role for Wolbachia in influencing fecundity.

Thirty generations postintrogression Fecundity effects were also investigated with mated females 30 generations after the introgression was completed. Table 5 shows results that are generally consistent with those of fecundity tests with virgin females. An ANOva on fecundities was conducted in the same fashion as above. Table 4 shows that once again, host strain had a consistent significant effect and was the main factor influencing fecundity. Infection status had a significant effect in the first ovipositioning period and on total fecundity. As before, this results from a reduction in fecundity of infected females in the 13.2 genetic background. Finally, there was no significant effect of the interaction term, except in the second ovipositioning period. This effect appears to be because of the decreased fecundity of infected females in the 13.2 genetic background, compared to the other two genetic backgrounds.

These results support the conclusion that increased fecundity of the original double-infected strain was caused by its nuclear background, not by its infection status.

\section{Discussion}

The classical view of symbiosis is that vertically transmitted symbionts will be selected to increase host survival and reproduction. The basic reason is that the invasion and maintenance of the symbiont is largely dependent upon host reproductive success. Thus, there is a long-standing prediction that heritable symbionts must evolve mutualisms with their hosts (Fine, 1975; Ewald, 1987; Yamamura, 1993; Lipsitch et al., 1995).

An exception to this classical view of mutualistic symbiosis is 'reproductive parasitism' (Werren \& O'Neill, 1997). Reproductive parasitism can facilitate the spread of vertically transmitted symbionts even when the infection poses a cost to host fitness. For example, Wolbachia infections that induce CI either decrease the fitness of uninfected females in diploid organisms (Hoffmann et al., 1990) or decrease the sex ratio of uninfected females in haplodiploids (Breeuwer \& Werren, 1990). Both mechanisms can ultimately cause an increase in the relative frequency of the symbiont even if it is detrimental to host fitness. Indeed, Drosophila simulans females infected with CI-inducing Wolbachia suffer a fecundity disadvantage (Hoffmann et al., 1990), yet the Wolbachia rapidly spread through Californian populations (Turelli \& Hoffmann, 1991). However, assuming perfect maternal transmission, Turelli (1994) showed theoretically that selection still acts to decrease fertility 


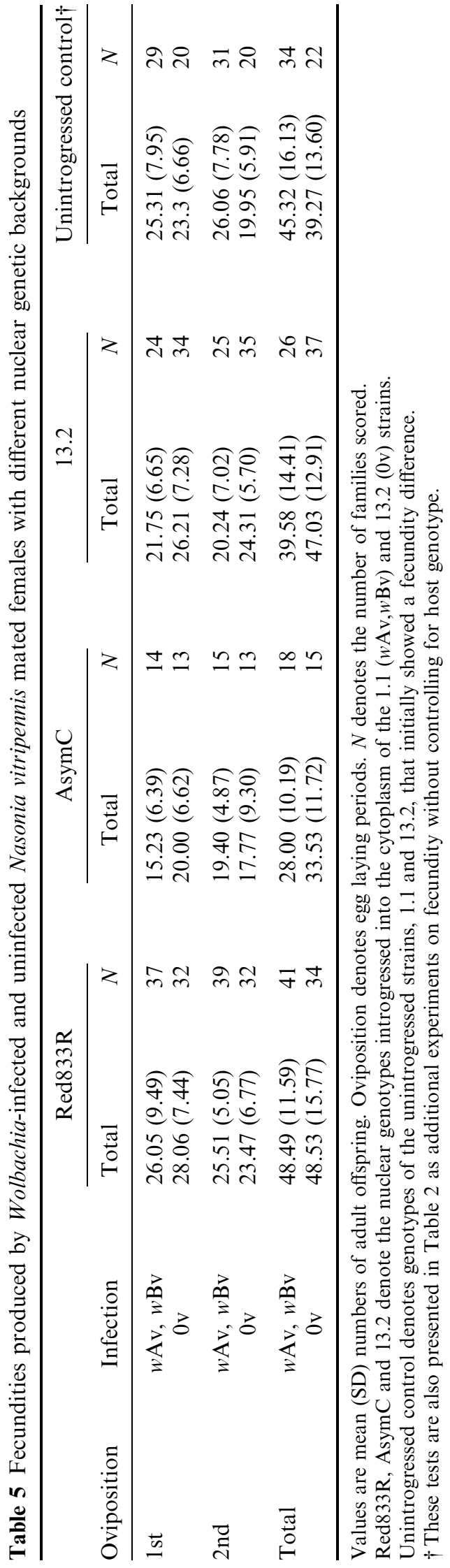

costs of the infection to females (e.g. increase fecundity of the transmitting host). In polymorphic populations with several compatible CI-inducing Wolbachia variants, the variant with the highest 'effective relative fecundity', measured as $F(1-\mu)$ where $F$ is relative fecundity of infected females and $(1-\mu)$ is transmission efficiency, will spread over competing Wolbachia variants.

In this study we examined whether Wolbachia influence female fecundity in the parasitoid wasp, Nasonia vitripennis, a species in which removal of the infection presumably caused a decrease in fecundity of uninfected females (Stolk \& Stouthamer, 1996).

Two patterns emerge from this study. First, Wolbachia tend not to pose a significant fecundity cost to females of Nasonia vitripennis. The absence of detrimental negative fitness effects is consistent with the prediction that selection favours heritable symbionts that do not harm their transmitting host. It is also consistent with phylogenetic evidence suggesting that Nasonia have relatively "ancient" Wolbachia infections (Werren et al., 1995b). Secondly, when host genetic background is controlled for, there is no evidence of a fitness benefit of the infection. Although the non-introgression $w \mathrm{Av}, w \mathrm{Bv}$ females yield a higher fecundity than the $0 \mathrm{v}$ females in four of the five replicate experiments, the differences disappeared when we controlled for genetic background by introgression. By introgressing three different $N$. vitripennis genotypes into double-infected and uninfected cytotypes, we determined that double-infected females do not have a higher fecundity in all three different nuclear backgrounds, and may have a lower fecundity in some cases. Additionally, the analyses of variance strongly indicated that host strain was the major factor influencing fecundity of both virgin and mated females, not infection status. Thus, Wolbachia do not appear to increase fecundity in $N$. vitripennis, in contrast to an earlier study by Stolk \& Stouthamer (1996).

One possible explanation for the difference is that we measured fecundity only over a limited ovipositioning period, whereas they measured lifetime fecundity. However, Stolk \& Stouthamer (1996) did not control for the host genetic changes associated with curing, whereas we have. In addition, their study only tested fecundity one generation after curing, whereas we have tested over multiple generations.

If Wolbachia do not increase female fecundity, then how can we explain the apparent fecundity difference in the initial lines? The lines were, after all, derived from a common ancestor in 1996 through a segregation experiment described in Perrot-Minnot et al. (1996). There are at least three explanations. First, if there was genetic variation present in the ancestral strain, then the derived 
parental strains may have become fixed for different nuclear genes influencing fecundity during the initial segregation of Wolbachia. Lines were subject to severe bottlenecks during the experiment because they were maintained through single females for several generations. Secondly, nuclear divergence may have occurred subsequent to the segregation experiment. The lines had been separately reared in small population cultures for over 40 generations before the study reported here. Either deleterious genes could have become fixed in the uninfected line or advantageous genes in the infected line. Thirdly, bacterial densities in the double-infected cytotype may have changed during our introgression experiment, leading to a loss of the apparent Wolbachia fecundity benefit. For example, fitness of the infected lines could decline because of higher bacterial densities that pose a load on females. Unfortunately, bacterial densities were not monitored in these strains.

We stress the need to control for the host genome as a critical variable influencing or causing phenomena attributed to Wolbachia. Increasing evidence shows that the host genome may influence Wolbachia-induced traits, such as the strength of cytoplasmic incompatibility (Bordenstein \& Werren, 1998; Poinsot et al., 1998; Perrot-Minnot \& Werren, 1999). Several methods have been developed to counter problems associated with nuclear divergence of infected and uninfected lines, including reciprocal crosses between infected and uninfected lines, mass rearing to reduce the effects of drift or inbreeding on nuclear divergence, and multiple comparisons of infected and uninfected field samples (Hoffmann et al., 1990; Poinsot \& Mercot, 1997; Hariri et al., 1998). Particularly effective methods to counter nuclear divergence effects include genomic 'replacement' by introgression, as used in this study, or microinjection of Wolbachia into different genetic backgrounds.

\section{Acknowledgements}

We thank A. Chawla, M. Drapeau, Y. Gottlieb, P. O'Hara and A. Ponce for their help with wasp transfers to new hosts. We also thank A. Hoffmann, S. Perlman, R. Stouthamer and an anonymous reviewer for critical comments on the manuscript. This research was supported by grants to J.H.W. from the National Science Foundation and the Binational Agricultural Research and Development Fund.

\section{References}

BORDENSTEIN, S. R. AND WERREN, J. H. 1998. Effects of A and B Wolbachia and host genotype on interspecies cytoplasmic incompatibility in Nasonia. Genetics, 144, 1833-1844.
BOURTZIS, K., NIRGIANAKI, A., MARKAKIS, G. AND SAVAKIS, C. 1996. Wolbachia infections and cytoplasmic incompatibility in Drosophila species. Genetics, 144, 1063-1073.

BREEUWER, J. A. J. AND WERREN, J. H. 1990. Microorganisms associated with chromosome destruction and reproductive isolation between two insect species. Nature, 346, 558-560.

CALlAINI, G., DALlAI, R. AND RIPARBELLI, M. G. 1997. Wolbachia-induced delay of paternal chromatin condensation does not prevent maternal chromosomes from entering anaphase in incompatible crosses of Drosophila simulans. J. Cell Sci., 110, 271-280.

EWALD, P. W. 1987. Transmission modes and the evolution of the parasitism-mutualism continuum. Ann. N.Y. Acad. Sci., 503, 295-306.

FINE, P. E. M. 1975. Vectors and vertical transmission: an epidemiologic perspective. Ann. N.Y. Acad. Sci., 266, 173-194.

FISHER, R. A. 1954. Statistical Methods for Research Workers, 12th edn. Oliver and Boyd, Edinburgh.

GIORDANO, R., O'NEILL, S. L. AND ROBERTSON, H. M. 1995. Wolbachia infections and the expression of cytoplasmic incompatibility in Drosophila sechellia and D. mauritiana. Genetics, 140, 1307-1317.

GIRIN, C. AND BOULETREAU, M. 1995. Microorganism-associated variation in host infestation efficiency in a parasitoid wasp, Trichogramma bourarachae (Hymenoptera, Trichogrammatidae). Experientia, 51, 398-401.

HARIRI, A. R., WERREN, J. H. AND WILKINSON, G. S. 1998. Distribution and fitness effects of Wolbachia in stalk-eyed flies (Diptera: Diopsidae). Heredity, 81, 254-260.

HOFFMANN, A. A. AND TURELLI, M. 1988. Unidirectional incompatibility in Drosophila simulans: inheritance, geographic variation and fitness effects. Genetics, 119, 435-444.

hofFMANN, A. A. AND TURELl, M. 1997. Cytoplasmic incompatibility in insects. In: O'Neill, S. L., Hoffmann, A. A. and Werren, J. H. (eds) Influential Passengers, pp. 42-80. Oxford University Press, Oxford.

hoffMAN, A. A., TURELl, M. AND Simmons, G. M. 1986. Unidirectional incompatibility between populations of Drosophila simulans. Evolution, 40, 692-701.

HOFFMANN, A. A., TURELli, M. AND HARSHMAN, L. G. 1990. Factors affecting the distribution of cytoplasmic incompatibility in Drosophila simulans. Genetics, 126, 933-948.

HOFFMANN, A. A., ClANCY, D. J. AND MERTON, E. 1994. Cytoplasmic incompatibility in Australian populations of Drosophila melanogaster. Genetics, 136, 993-999.

HOFFMANN, A. A., CLANCY, D. J. AND DUNCAN, J. 1996. Naturally-occurring. Wolbachia infection in Drosophila simulans that does not cause cytoplasmic incompatibility. Heredity, 76, 1-8.

HOLM, S. 1979. A simple sequentially rejected multiple test procedure. Scand. J. Stat., 6, 65-70.

HURST, G. D. D. AND MAJERUS, M. E. N. 1993. Why do maternally inherited microorganisms kill males? Heredity, 71, 81-95.

JOHANOWICZ, D. L. AND HOY, M. A. 1995. Molecular evidence for A-Wolbachia endocytobiont in the predatory mite Metaseiulus occidentalis. J. Cell. Biochem., 21A, 198. 
LIPSITCH, M., NOWAK, M. A., EBERT, D. AND MAY, R. M. 1995. The population dynamics of vertically and horizontally transmitted parasites. Proc. R. Soc. B, 260, 321-327.

O'NEILL, S. L. AND KARR, T. L. 1990. Bidirectional incompatibility between conspecific populations of Drosophila simulans. Nature, 348, 178-180.

PERROT-MINNOT, M. J., GUO, L. R. AND WERREN, J. H. 1996. Single and double infections with Wolbachia in the parasitic wasp Nasonia vitripennis: effects on compatibility. Genetics, 143, 961-972.

PERROT-MINNOT, M. J. AND WERREN, J. H. 1999. Wolbachia infection and incompatibility dynamics in experimental selection lines. J. Evol. Biol., 12, 272-282.

POINSOT, D. AND MERCOT, H. 1997. Wolbachia infection in Drosophila simulans: does the female host bear a physiological cost? Evolution, 51, 180-186.

POINSOT, D., BOURTZIS, K., MARKAKIS, G., SAVAKIS, C. AND MERCOT, H. 1998. Wolbachia transfer from Drosophila melanogaster into D. simulans: host effect and cytoplasmic incompatibility relationships. Genetics, 150, 227-237.

REED, K. M. AND WERREN, J. H. 1995. Induction of paternal genome loss by the paternal sex ratio chromosome and cytoplasmic incompatibility bacteria (Wolbachia): a comparative study of early embryonic events. Mol. Reprod. Devel., 40, 408-418.

ROUSSET, F., BOUCHON, D., PINTUREAU, B., JUCHAUlT, P. AND SOLIGNAC, M. 1992. Wolbachia endosymbionts responsible for various alterations of sexuality in arthropods. Proc. $R$. Soc. B., 250, 91-98.

RYAN, S. L. AND SAUL, G. B. 1968. Post-fertilization effect of incompatibility factors in Mormoniella. Mol. Gen. Genet., 103, 29-36.

SIRONI, M., BANDI, C., SACCHI, L., SACCO, B. D., DAMIANI, G. AND GENCHI, C. 1995. Molecular evidence for a close relative of the arthropod endosymbiont Wolbachia in a filarial worm. Mol. Biochem. Parasit., 74, 223-227.

SOKAL, R. R. AND ROHLF, F. J. 1981. Biometry, 2nd edn. W. H. Freeman, San Francisco, CA.

STOLK, C. AND STOUTHAMER, R. 1996. Influence of a cytoplasmic incompatibility-inducing Wolbachia on the fitness of the parasitoid wasp Nasonia vitripennis. Proc. Exp. Appl. Entomol, N.E.V. Amsterdam, 7, 33-37.

STOUTHAMER, R. AND LUCK, R. F. 1993. Influence of microbe associated parthenogenesis on the fecundity of Trichogramma deion and T. pretiosum. Entomologia. exp. appl., 67, 183-192.

STOUTHAMER, R., BREEUWER, J. A. J., LUCK, R. F. AND WERREN, J. H. 1993. Molecular identification of microorganisms associated with parthenogenesis. Nature, 361, 66-68.

TURELLI, M. 1994. Evolution of incompatibility-inducing microbes and their hosts. Evolution, 48, 1500-1513.

TURELLI, M. AND HOFFMANN, A. A. 1991. Rapid spread of an inherited incompatibility factor in California Drosophila. Nature, 353, 440-442.

vavre, F., Girin, C. AND Bouletreau, M. 1999. Phylogenetic status of a fecundity-enhancing Wolbachia that does not induce thelytoky in Trichogramma. Insect Mol. Biol., 8, $67-72$.

WADE, M. J. AND CHANG, N. W. 1995. Increased male fertility in Tribolium confusum beetles after infection with the intracellular parasite Wolbachia. Nature, 373, 72-74.

Werren, J. H. 1997. Biology of Wolbachia. Ann. Rev. Ent., 42, 587-609.

WERREN, J. H. AND O'NEILL, S. L. 1997. The evolution of heritable symbionts. In: O'Neill, S. L., Hoffmann, A. A. and Werren, J. H. (eds) Influential Passengers, pp. 1-41. Oxford University Press, Oxford.

WERREN, J. H., GUO, L. W. AND WINDSOR, D. W. 1995a. Distribution of Wolbachia in neotropical arthropods. Proc. R. Soc. B, 262, 197-204.

WERREN, J. H., GUO, L. W. AND ZHANG, w. 1995b. Evolution and phylogeny of Wolbachia: reproductive parasites of arthropods. Proc. R. Soc. B, 261, 55-71.

Whiting, A. R. 1967. The biology of the parasitic wasp Mormoniella vitripennis. Q. Rev. Biol., 42, 333-406.

YAMAMURA, N. 1993. Vertical transmission and evolution of mutualism from parasitism. Theor. Pop. Biol., 44, 95-109.

YEN, J. H. AND BARR, A. R. 1971. New hypothesis of the cause for cytoplasmic incompatibility in Culex pipiens. Nature, 232, 657-658. 